\title{
A STUDY OF ATRIAL FIBRILLATION IN RHEUMATIC HEART DISEASE
}

\author{
Jyotirmayi Bodduํ, V. C. Srinivas Reddy 2 \\ ${ }_{1}^{1}$ Assistant Professor, Department of General Medicine, Andhra Medical College, Visakhapatnam, Andhra Pradesh. \\ ${ }^{2}$ Assistant Professor, Department of General Medicine, Andhra Medical College, Visakhapatnam, Andhra Pradesh.
}

\section{ABSTRACT}

\section{BACKGROUND}

Atrial fibrillation is the most common sustained arrhythmia in clinical practice. Among Indians, rheumatic heart disease is the most common aetiological factor.

In this study, we have evaluated atrial fibrillation in patients with chronic rheumatic heart disease.

\section{MATERIALS AND METHODS}

This was a retrospective observational study. Case sheets of 75 patients fulfilling the inclusion criteria were studied. The clinical data and 2D echocardiography findings of the patients were studied.

\section{RESULTS}

$51(68 \%)$ patients belonged to 21 to 40 years' age group. Females were more than males. $62(82.7 \%)$ patients presented with dyspnoea followed by palpitations in 34 (45.3\%). 70 (93\%) had mitral stenosis. 39 (52\%) had combined mitral stenosis with regurgitation. The mean left atrial size was $4.87 \mathrm{~cm} .34(45.3 \%)$ of total patients had clot in left atrium. Among the various valvular lesions, mitral stenosis had 33 (44\%) of left atrial clot. Among mitral stenosis, 55 (78.6\%) had severe stenosis with 30 (54.5\%) of them having a left atrial clot.

\section{CONCLUSION}

The analysis of the present study gives us insight into the various aspects of valvular involvement in the patients of rheumatic heart disease with atrial fibrillation.

\section{KEYWORDS}

Atrial Fibrillation, Rheumatic Heart Disease, Arrhythmia, Mitral Stenosis, Mitral Regurgitation.

HOW TO CITE THIS ARTICLE: Boddu J, Reddy VCS. A study of atrial fibrillation in rheumatic heart disease. J. Evolution Med. Dent. Sci. 2018;7(08):1020-1023, DOI: 10.14260/jemds/2018/233

\section{BACKGROUND}

Atrial fibrillation is a supraventricular tachyarrhythmia characterised by chaotic uncoordinated atrial activation leading to deterioration of atrial function. It is the most common sustained arrhythmia in clinical practice. ${ }^{1}$

Development of atrial fibrillation contributes to significant morbidity and mortality. ${ }^{2}$ It increases mortality by 2 -fold. The risk ratio is 1.5 for men and 1.9 for women. ${ }^{3}$ The risk of stroke increases by 5 -fold. 4

Atrial fibrillation is caused by various cardiac conditions like hypertension, coronary artery disease, valvular heart disease, congestive heart failure, cardiomyopathy, congenital heart disease, cardiac surgery and non-cardiac conditions like chronic obstructive pulmonary disease, acute pulmonary embolism, obstructive sleep apnoea and hyperthyroidism.

The overall prevalence of atrial fibrillation is estimated to be $0.4 \%$ to $1 \%$ in general population. ${ }^{5}$ In western countries, hypertensive heart disease, coronary heart disease and dilated cardiomyopathy are common causes. In India, rheumatic fever as well as rheumatic heart disease are more

'Financial or Other Competing Interest': None.

Submission 12-01-2018, Peer Review 05-02-2018,

Acceptance 12-02-2018, Published 19-02-2018.

Corresponding Author:

Dr. V. C. Srinivas Reddy,

GF 5, Nagamalli Apartments,

Opp. Old Fire Station,

Dandu Bazar Road, Maharanipeta,

Visakhapatnam-530002, Andhra Pradesh.

E-mail: drboddudgo2001@yahoo.com

DOI: $10.14260 / \mathrm{jemds} / 2018 / 233$ prevalent than in the west. As a consequence, among Indians, rheumatic heart disease is the most common aetiological factor of atrial fibrillation. ${ }^{6}$ Rheumatic heart disease usually affects the young and productive age group population. This leads to huge health burden and economic implications to the patients, their families and society.

So, we have studied the patients with chronic rheumatic heart disease with atrial fibrillation. We have evaluated the clinical features and the 2D Echocardiography findings with regard to the valve involvement and its severity, left atrial size, left atrial clot in patients with chronic rheumatic heart disease with atrial fibrillation in this study.

\section{Objective}

To study the clinical and 2D echocardiography profiles of patients of rheumatic heart disease with atrial fibrillation.

\section{MATERIALS AND METHODS}

This was a retrospective observational study conducted in the medical wards of King George Hospital, a tertiary care teaching hospital in Visakhapatnam, Andhra Pradesh. Case sheets of 75 patients with chronic rheumatic heart disease with atrial fibrillation were included in the study. To diagnose atrial fibrillation, electrocardiography showing absent ' $p$ ' waves, fibrillatory waves with irregularly irregular ventricular response and varying R-R interval were included. The clinical data and 2D echocardiography findings of the patients were studied and analysed.

Patients with atrial fibrillation of other aetiologies were excluded. Appropriate statistical methods employed to 
analyse the data. Data analysis was done using Microsoft Excel. Results are presented as percentages.

\section{RESULTS}

\begin{tabular}{|c|c|c|c|c|}
\hline Age (Years) & Males & Females & Total & $\%$ \\
\hline$<20$ & 3 & 2 & 5 & 6.7 \\
\hline $21-30$ & 11 & 9 & 20 & 26.7 \\
\hline $31-40$ & 13 & 18 & 31 & 41.3 \\
\hline $41-50$ & 4 & 10 & 14 & 18.7 \\
\hline $51-60$ & 1 & 2 & 3 & 4 \\
\hline$>60$ & 1 & 1 & 2 & 2.7 \\
\hline Total & $33(44 \%)$ & $42(56 \%)$ & 75 & 100 \\
\hline Mean & $\begin{array}{c}33.091+/- \\
9.586\end{array}$ & $\begin{array}{c}37.262+/- \\
10.567\end{array}$ & & \\
\hline
\end{tabular}

\section{Female: Male - 1.27: 1}

$31(41.3 \%)$ patients belonged to 31 to 40 years' age group, 5 $(6.7 \%)$ patients belonged to $<20$ years' age group. $1(2 \%)$ was $>60$ years. Mean age among males was $33.091+/-9.586$ and was $37.262+/-10.567$ among females. Out of 75, 42 $(56 \%)$ were females and $33(44 \%)$ were males. Female-tomale ratio was 1.27 to 1 .

\begin{tabular}{|c|c|c|}
\hline Symptoms & No. of Patients & $\mathbf{\%}$ \\
\hline Dyspnoea & 62 & 82.7 \\
\hline Palpitations & 34 & 45.3 \\
\hline Pedal oedema & 21 & 28 \\
\hline Chest pain & 14 & 18.7 \\
\hline Hemiplegia & 7 & 9.3 \\
\hline Haemoptysis & 1 & 1.3 \\
\hline \multicolumn{3}{|c|}{ Table 2. Symptoms } \\
\hline
\end{tabular}

Among the symptoms of presentation, 62 (82.7\%) patients presented with dyspnoea followed by palpitations in 34 (45.3\%), pedal oedema in 21 (28\%) and 14 (18.7\%) had chest pain. $7(9.3 \%)$ patients presented with hemiplegia. 1 (1.3\%) patient presented with haemoptysis.

\begin{tabular}{|c|c|c|}
\hline Valvular Lesion & No. of Patients & $\mathbf{\%}$ \\
\hline MS (Total) & 70 & $93.3 \%$ \\
\hline MR (Total) & 44 & $58.7 \%$ \\
\hline AR (Total) & 19 & $25.3 \%$ \\
\hline AS (Total) & 4 & $5.3 \%$ \\
\hline MS + MR & 39 & $52 \%$ \\
\hline MS + AR & 17 & $22.7 \%$ \\
\hline MR + AR & 3 & $4 \%$ \\
\hline MS + MR + AR & 12 & $16 \%$ \\
\hline MS + MR + AR + AS & 3 & $4 \%$ \\
\hline Isolated MS & 26 & $34.7 \%$ \\
\hline Isolated MR & 2 & $2.7 \%$ \\
\hline Isolated AR & - & - \\
\hline Isolated AS & - & - \\
\hline \multicolumn{2}{|c|}{ Table 3. Valvular Lesions } \\
\hline
\end{tabular}

MS- Mitral Stenosis; MR- Mitral Regurgitation; AR- Aortic Regurgitation; AS- Aortic Stenosis.

$70(93 \%)$ had mitral stenosis. $39(52 \%)$ had combined mitral stenosis with regurgitation. Isolated mitral stenosis was found in $26(34.7 \%)$. Mitral regurgitation was present in $44(58.7 \%) .2(2.7 \%)$ had isolated mitral regurgitation. 12 $(16 \%)$ had mitral stenosis with regurgitation and aortic regurgitation. $3(4 \%)$ had mitral stenosis with regurgitation and aortic stenosis with regurgitation.

\begin{tabular}{|c|c|c|}
\hline LA Size (cms) & No. of Patients & $\mathbf{\%}$ \\
\hline$<4$ & 28 & $37.3 \%$ \\
\hline$>4$ & 47 & $62.7 \%$ \\
\hline Total & $\mathbf{7 5}$ & $\mathbf{1 0 0}$ \\
\hline Mean & $4.87 \mathrm{~cm}$ & \\
\hline \multicolumn{3}{|c|}{ Table 4. Left Atrial (LA) Size } \\
\hline
\end{tabular}

Left atrial size $>4 \mathrm{~cm}$ was present in 47 (62.7\%) patients. The mean left atrial size was $4.87 \mathrm{~cm}$.

\begin{tabular}{|c|c|c|c|}
\hline LA Size (cms) & No. of Patients & LA Clot & \% \\
\hline$<4$ & 28 & 9 & 32.1 \\
\hline$>4$ & 47 & 25 & 53.1 \\
\hline Total & $\mathbf{7 5}$ & $\mathbf{3 4}$ & $\mathbf{4 5 . 3}$ \\
\hline Mean & 4.87 CM & & \\
\hline \multicolumn{4}{|c|}{ Table 5. Left Atrial (LA) Size and Clot } \\
\hline
\end{tabular}

$34(45.3 \%)$ of total patients had clot in left atrium. 25 (53\%) with left atrium size $>4 \mathrm{~cm}$ had LA clot. Among patients with left atrial size $<4 \mathrm{cms}, 9(32.1 \%)$ had clot in the left atrium.

\begin{tabular}{|c|c|c|c|c|}
\hline Valvular Lesion & No. of Patients & $\mathbf{\%}$ & LA Clot & \% \\
\hline MS (Total) & 70 & $93.3 \%$ & 33 & 44 \\
\hline MR (Total) & 44 & $58.7 \%$ & 20 & 26.7 \\
\hline AR (Total) & 19 & $25.3 \%$ & 8 & 10.7 \\
\hline AS (Total) & 4 & $5.3 \%$ & 2 & 2.7 \\
\hline MS + MR & 39 & $52 \%$ & 19 & 25.3 \\
\hline MS + AR & 17 & $22.7 \%$ & 7 & 9.3 \\
\hline MR + AR & 3 & $4 \%$ & 1 & 1.3 \\
\hline MS + MR + AR & 12 & $16 \%$ & 5 & 6.7 \\
\hline MS + MR + AR + AS & 3 & $4 \%$ & 2 & 2.7 \\
\hline Isolated MS & 26 & $34.7 \%$ & 14 & 18.7 \\
\hline Isolated MR & 2 & $2.7 \%$ & - & - \\
\hline Isolated AR & - & - & - & - \\
\hline Isolated AS & - & - & - & - \\
\hline Table 6. Valvular Lesions and Left Atrial (LA) Clot \\
\hline
\end{tabular}

Among the various valvular lesions, mitral stenosis had $33(44 \%)$ of left atrial clot. $19(25.3 \%)$ patients of mitral stenosis with regurgitation had a left atrial clot. $14(18.7 \%)$ of isolated mitral stenosis had clot in left atrium.

\begin{tabular}{|c|c|c|c|c|}
\hline Mitral Stenosis & No. of Patients & $\mathbf{\%}$ & LA Clot & $\mathbf{\%}$ \\
\hline Mild & 1 & 1.42 & - & 0 \\
\hline Moderate & 14 & 20 & 3 & 21.4 \\
\hline Severe & 55 & 78.6 & 30 & 54.5 \\
\hline Total & $\mathbf{7 0}$ & $\mathbf{1 0 0}$ & $\mathbf{3 3}$ & $\mathbf{4 7 . 1}$ \\
\hline Table 7. Severity of Valvular Lesions- Mitral Stenosis \\
\hline
\end{tabular}

Among mitral stenosis, 55 (78.6\%) had severe stenosis with $30(54.5 \%)$ of them having a left atrial clot. $14(20 \%)$ had moderate mitral stenosis with $3(21.4 \%)$ with left atrial clot. Only 1 patient had mild stenosis.

\begin{tabular}{|c|c|c|c|c|}
\hline $\begin{array}{c}\text { Mitral } \\
\text { Regurgitation }\end{array}$ & $\begin{array}{c}\text { No. of } \\
\text { Patients }\end{array}$ & $\mathbf{\%}$ & LA Clot & \% \\
\hline Mild & 17 & 38.7 & 10 & 58.8 \\
\hline Moderate & 24 & 54.5 & 7 & 29.1 \\
\hline Severe & 3 & 6.8 & 3 & 100 \\
\hline Total & $\mathbf{4 4}$ & $\mathbf{1 0 0}$ & $\mathbf{2 0}$ & $\mathbf{4 5 . 5}$ \\
\hline
\end{tabular}

Table 8. Severity of Valvular Lesions- Mitral Regurgitation 
Among mitral regurgitation, 24 (54.5\%) had moderate severity with $7(29.1 \%)$ of them having a left atrial clot. 3 $(6.8 \%)$ had severe regurgitation and all of them $(100 \%)$ had a clot in the left atrium. 17 (38.7\%) had mild regurgitation and $10(58.8 \%)$ of them had a left atrium clot.

\section{DISCUSSION}

Atrial fibrillation is the most common sustained cardiac arrhythmia in clinical practice and is associated with substantial morbidity and mortality. ${ }^{7}$

Among Indians, unlike the western countries, chronic rheumatic heart disease is the predominant aetiology of atrial fibrillation. In our country rheumatic fever and rheumatic heart disease are more prevalent compared to the west. In a study by Jacob Jose in 2002, prevalence of rheumatic heart disease was found to be $0.68 / 1000$ children. ${ }^{8}$ The adult average prevalence is between 123 and 200/100,000 population, ${ }^{9}$ whereas in the industrialised nations it is less than $0.05 / 1000 .{ }^{10}$ According to the first Indian registry, the Indian Heart Rhythm Society (IHRS) AF study, ${ }^{11}$ rheumatic heart disease remained the most common aetiology of atrial fibrillation at $42 \%$. In a study by Bhardwaj R, rheumatic heart disease was the aetiology of atrial fibrillation in $61.31 \%$ patients. $^{12}$ In a study by SK Sharma, the incidence of atrial fibrillation was $43.61 \%$ among patients of rheumatic heart disease. 13

In our study, the majority of patients were in the $21-40$ years' age group, i.e. $51(68 \%)$ of patients belonged to 21 to 40 years' age group. $41.3 \%$ were 31 to 40 years' age group. Mean age among males was 33 years and was 37 years among females. Only $5(6.7 \%)$ patients belonged to less than 20 years' age group and only $1(2 \%)$ were $>60$ years. In the study by SK Sharma, 55\% patients were in the age group of $21-30$ yrs. ${ }^{13}$

Out of 75, $42(56 \%)$ were females and 33 (44\%) were males. Female-to-male ratio was 1.27 to 1 . This is similar to findings in other studies. Women participants were $51 \%$ in the Indian Heart Rhythm Society (IHRS) AF study. ${ }^{11}$ In the study by Bhardwaj $\mathrm{R} 55.47 \%$ were females ${ }^{12}$ and in SK Sharma's study $72.72 \%$ were females. ${ }^{13}$

Majority of patients with atrial fibrillation are relatively asymptomatic. Others can present with varied symptoms due to rapid or slow ventricular rates, failing atrial systolic function and the development of atrial thrombus with subsequent embolic stroke. In this study, the most common symptom of presentation was dyspnoea in $62(82.7 \%)$ patients followed by palpitations in 34 (45.3\%), pedal oedema in 21 (28\%) and $14(18.7 \%)$ had chest pain. 1 (1.3\%) patient presented with haemoptysis. These were in concordance with study by Dharma Rao V et al who observed dyspnoea in $83.67 \%$, palpitations in $53.06 \%$ and chest pain in $30.61 \%$ as the most common presentations. ${ }^{14}$ In the study by Lok NS, dyspnoea and palpitations were the most common symptoms. ${ }^{15}$ In the present study, 7 (9.3\%) patients presented with hemiplegia and in the study by Dharma Rao V et al, stroke was seen in $13.33 \%$ of cases. ${ }^{14}$ The risk of stroke with atrial fibrillation increases with age.

Normal size of left atrium is $19 \mathrm{~mm}$ to $40 \mathrm{~mm}$. Left atrial enlargement is considered to be present if it is more than 40 $\mathrm{mm}$. Left atrial enlargement is attributed to change in the left atrial pressure consequent to valvular obstruction in chronic rheumatic heart disease. In the present study, left atrial size >
$4 \mathrm{~cm}$ was present in $47(62.7 \%)$ patients. In the study by Henry WL et al $54 \%$ patients had AF, when LA size was $>40$ mm. ${ }^{16}$ The mean left atrial size in the present study was 4.87 $\mathrm{cm}$. In a study by G. Singh et $\mathrm{al}^{17}$ patients with rheumatic heart disease with atrial fibrillation had mean LA size of 50.2 $\mathrm{mm}$. Mrozowska et al,18 in their study said atrial fibrillation was rare when LA dimension was $<40 \mathrm{~mm}$. In the present study, 28 (37.3\%) had LA $<4 \mathrm{~cm}$. Left atrial enlargement in atrial fibrillation is associated with worsening of functional status, development of pulmonary arterial hypertension and congestive cardiac failure. Embolic complications like stroke were more in patients with atrial fibrillation and left atrial dilatation. In the present study, $34(45.3 \%)$ of total patients had clot in left atrium. LA clot was present in 25 (53\%) of patients with enlarged LA size, i.e. $>4 \mathrm{~cm}$ and only in 9 (32.1\%) with normal LA size of $<4 \mathrm{~cm}$.

In the present study, most common valvular involvement was mitral stenosis with 70 (93\%) patients. In a study by Radha Krishnan, out of 100 cases of acquired valvular heart disease the maximum brunt is borne by mitral valve and was involved in 56\%, 27\% had isolated mitral stenosis, $14 \%$ cases had isolated mitral regurgitation, $17 \%$ cases had mitral stenosis and mitral regurgitation, $13 \%$ cases were aortic stenosis with aortic regurgitation and $26 \%$ with multivalvular heart disease. ${ }^{19}$ In comparison our study had higher percentage involvement of mitral valve disease, 70 (93\%) with mitral stenosis, 39 (52\%) had combined mitral stenosis and regurgitation, isolated mitral stenosis in 26 (34.7\%), mitral regurgitation in $44(58.7 \%)$ and $2(2.7 \%)$ had isolated mitral regurgitation. $12(16 \%)$ had mitral stenosis with regurgitation and aortic regurgitation. $3(4 \%)$ had mitral stenosis with regurgitation with aortic stenosis with regurgitation. The above differences could be explained by the patient's groups included in the study. Our study had included only patients with atrial fibrillation. Mitral valve disease causes left atrial dilatation, which is a common substrate for atrial fibrillation.

Among the total study patients left atrial clot was present in $33(44 \%)$ cases of mitral stenosis, $20(26.7 \%)$ of mitral regurgitation, $19(25.3 \%)$ patients of mitral stenosis with regurgitation, $14(18.7 \%)$ of isolated mitral stenosis, 7 (9.3\%) of mitral stenosis with AR, $5(6.7 \%)$ of mitral stenosis with mitral regurgitation and aortic regurgitation. Mitral valve disease causes left atrial dilatation, is the substrate for atrial fibrillation and its complications like clot formation in the atrium.

Mitral stenosis was the most common valvular lesion found in $70(93 \%)$ cases and of them 33 (47.1\%) had left atrial clots. Among them majority had severe stenosis, i.e. 55 $(78.6 \%)$ with $30(54.5 \%)$ of them had a clot in left atrium. Moderate mitral stenosis was present in only 20\% (14) with $21.4 \%$ (3) of them with LA clot. The single mild mitral stenosis patient had mixed lesion of mitral stenosis with mitral regurgitation and aortic regurgitation. This is concurring with the findings of other studies. Various studies point towards the incidence of left atrial thrombus in upto $50 \%$ of patients with rheumatic mitral stenosis. In a study by Karatasaki et al of mitral stenosis and atrial fibrillation, left atrial thrombus was observed in $54 \% .{ }^{20}$ In another study of mitral stenosis and atrial fibrillation by Hwang et al, the incidence of left atrial thrombus was $56 \% .{ }^{21}$ In the study by Srimannarayana et al, they found left atrial clots in a third of 
patients with severe rheumatic mitral stenosis and atrial fibrillation. ${ }^{22}$

Next common valvular involvement was mitral regurgitation in $44(45.5 \%)$ of study group with 20 (26.7\%) with LA clot. 24 (54.5\%) of them had moderate severity lesion and 7 (29\%) of them had left atrial clot. $3(6.8 \%)$ had severe regurgitation and all of them $(100 \%)$ had a clot in left atrium. 17 (38.7\%) had mild regurgitation and 10 (58.8\%) of them had a left atrium clot. But out of 44 patients with mitral regurgitation, only 2 were isolated mitral regurgitation, remaining 42 were mixed lesions associated with mitral stenosis and/or aortic regurgitation and/or aortic stenosis.

\section{CONCLUSION}

Most common aetiological factor for atrial fibrillation in Indian scenario is rheumatic heart disease. It affects the younger age group patients when compared to other causes of atrial fibrillation. In our study, females were more than males. Breathlessness was the most common symptom. Majority of them had a dilated left atrial chamber. Mitral stenosis was the most common valvular lesion followed by mitral regurgitation. Significant percentage of patients had severe disease and a left atrial clot. This predisposes them to increased risk of complications like systemic embolisation and also increased mortality. The analysis of the present study gives us insight into the various aspects of valvular involvement in the patients of rheumatic heart disease with atrial fibrillation. This emphasises the need for early detection and planning of early treatment of rheumatic fever and rheumatic heart disease to prevent the progression and development of complications. The limitation of this study is that it is single centre study with limited subjects. A large multicentre study may help to understand and analyse in much more detail about various factors of rheumatic heart disease contributing to development of atrial fibrillation and its complication, a condition which is still causing a substantial morbidity and mortality in young and productive age group population of India.

\section{REFERENCES}

[1] Lip GYH, Beevers DG. ABC of atrial fibrillation. History, epidemiology and importance of atrial fibrillation. BMJ 1995;311(7016):1361-3.

[2] Cox JL. Atrial fibrillation I. A new classification system. J Thoracic Cardiovascular Surgery 2003;126(6):168692.

[3] Rasoli S, Kakouros N, Harling L, et al. Antioxidant vitamins in the prevention of atrial fibrillation. What is the evidence? Article ID 164078, Cardiology Research and Practice 2011;2011: p. 8.

[4] Serrano CM, Hernández-Madrid A, de Arritmias U. Atrial fibrillation. Is it an Epidemic? Rev Esp Cardiol 2009;62(1):10-4.

[5] Fuster V, Rydén LE, Cannom DS, et al. ACC/AHA/ESC 2006 Guidelines for the management of patients with atrial fibrillation. Circulation 2006;114(7):700-52.
[6] Vora A. Approach to management of atrial fibrillation in the Indian scenario. Supplement of JAPI 2007;55:30-3.

[7] Tyagi S, Mukhopadhyay S, Gupta MD. Atrial fibrillation from Bench to bedside. Cardiology Today 2004;8(6): 289-300.

[8] Jose VJ, Gomathi M. Declining prevalence of rheumatic heart disease in rural school children in India: 20012002. Indian Heart J 2003;55(2):158-60.

[9] Mathur KS, Wahal PK. Epidemiology of rheumatic heart disease. A study of 29,922 school children. Indian Heart Journal 1982;34:367-71.

[10] Padmavati S. Rheumatic fever and rheumatic heart disease in developing countries. Bull WHO 1978;56(4):543-50.

[11] IHRS AF Registry presented in ISE Meeting. Mumbai, 2011.

[12] Bhardwaj R. Atrial fibrillation in a tertiary care institute - a prospective study. Indian Heart J 2012;64(5):476-8.

[13] Sharma SK, Verma SH. A clinical evaluation of atrial fibrillation in rheumatic heart disease. J Assoc Physicians India 2015;63(6):22-5.

[14] Rao DV, Reddy RM, Srikanth K, et al. To study the prevalence and clinical profile of chronic atrial fibrillation in hospitalized patients. NUJHS 2014;4(2):17-20.

[15] Lok NS, Lau CP. Presentation and management of patients admitted with atrial fibrillation. A review of 291 cases in a regional hospital. International J of Cardiology 1995;48(3):271-8.

[16] Henry WL, Morgantroth J, Pearlman AS, et al. Relation between echocardiographically determined left atrial size and atrial fibrillation. Circulation 1976;53(2): 273-9.

[17] Singh G, Arora P. Study of left atrial size in atrial fibrillation. JAPI 2002;50:50.

[18] Mrozowska E, Rogowski W, Musial WJ, et al. Atrial fibrillation in mitral valve disease-risk factors. Pol Arch Med Wewn 1999;1010(1):45-53.

[19] Krishnan DR, Srinivas V. The study of prevalence and clinical profile of valvular heart diseases in a teaching hospital Andhra Pradesh. Journal of Evidence Based Medicine and Healthcare 2015;2(18):2707-18.

[20] Karatasakis GT, Gotsis AC, Cokkinos DV. Infleunce of mitral regurgitation on left thrombus and spontaneous echocardiographic contrast in patients with rheumatic mitral valve disease. Am J Cardiol 1995;76(4):279-81.

[21] Hwang JJ, Chen JJ, Lin SC, et al. Diagnostic accuracy of transesophageal echocardiography for detecting left atrial thrombi in patients with rheumatic heart disease having under gone mitral valve operations. Am J Cardiol 1993;72(9):677-81.

[22] Srimannarayana J, Varma RS, Satheesh S, et al. Prevalence of left atrial thrombus in rheumatic mitral stenosis with atrial fibrillation and its response to anticoagulation. A transesophageal echocardiographic study. Indian Heart Journal 2003;55(4):358-61. 